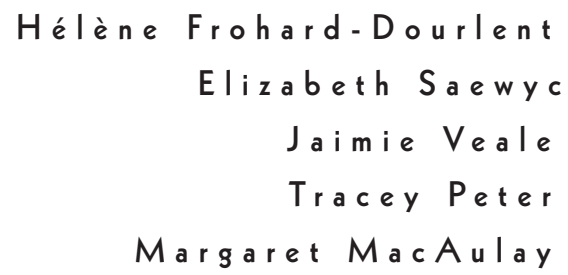

\title{
Conceptualizing Gender: Lessons from the Canadian Trans Youth Health Survey
}

n 2016, when Canadians were asked to fill out the mandatory census, they were asked "what is [your] sex?" with only two options available: female and male. Activists immediately raised concerns about this question: what option were nonbinary respondents supposed to choose? ${ }^{1}$ Statistics Canada representatives responded that trans and intersex Canadians should select the gender with which they most associate themselves or leave the question blank and indicate in the comments their reason(s) for choosing not to answer that question (Kupfer 2016), and they were promised a public consultation on the topic ahead of the 2021 Census, which is currently underway (Grant 2018).

This issue speaks to the growing activism of trans people and the resulting visibility of questions about gender and gender identity. ${ }^{2}$ It also speaks to the difficulty of asking about gender and sex in a coherent and inclusive way in large-scale surveys. For example, while Statistics Canada's census question used the term "sex," their representatives responded by using "gender." Yet the two are not synonymous. It has become common to define sex as a medical and social categorization assigned at birth, based on a set of biological attributes, while gender is a fundamental aspect of self-identity that can be expressed through roles, behaviors, appearances, or identities (CIHR 2015). Someone's sex, then, can differ from their gender. Asking about sex versus gender means collecting different data. Simply adding a nonbinary option to the census question may create confusion if the terminology used

This study was funded by grant \#MOP 119472 from the Canadian Institutes of Health Research.

${ }^{1}$ We use "nonbinary" as an (imperfect) umbrella term for people whose gender falls outside of the binary categories of men and women.

${ }^{2}$ We use the word "trans" as an umbrella term to be inclusive of people who identity as trans, transgender, transsexual, and nonbinary, although we recognize the limits of this inclusion (Davidson 2007).

[Signs: Journal of Women in Culture and Society 2020, vol. 46, no. 1]

(C) 2020 by The University of Chicago. All rights reserved. 0097-9740/2020/4601-0007\$10.00 
is not understood similarly by everyone. When we designed the first iteration of the Canadian Trans Youth Health Survey (CTYHS) in 2013, one of our goals was to provide some insights into questions about gender identity and how researchers can best ask about gender and sex in large-scale population surveys in order to account for people of all genders, whether they be trans or cisgender. ${ }^{3}$ In this article, we use data from this survey to illustrate youth respondents' nuanced, multiple, and at times inconsistent understandings of gender and sex. We show that youth used the language of social construction and bioessentialism in ways that both converge in how they legitimize trans people's genders and yet also sit in tension with each other because they suggest very different ways of redoing or undoing notions of sex and gender.

A key observation from some trans youth respondents' understandings of sex and gender is that while mainstream discourse constructs sex as fixed and gender as mutable, some CTYHS respondents articulated an opposite perspective: that gender is fixed and sex is mutable. Many respondents - particularly binary trans youth-framed gender as the core of a person's inner "truth," with transition representing a way to correct a person's assigned sex at birth. We partly attribute this to the popularity of narratives about "being born in the wrong body" or having a "boy brain in a girl's body," which frames trans subjectivities as medical problems with medical solutions. Youth challenged the authority granted to medical actors who assigned their sex at birth, even as some reinvested it through medical interventions like hormone replacement therapies and/or gender-affirming surgeries. Inverting social constructionist and essentialist perspectives on gender and sex, this perspective demonstrates how youth do, undo, and redo trans subjectivities in a cultural context that increasingly recognizes them. We conclude by exploring the implications these understandings have for how we incorporate questions about gender and sex into our research, including the need to continually engage youth in research design.

\section{Literature review}

Before our analysis of how youth discussed gender and sex in the CTYHS, these discussions should be contextualized within a history of feminist scholarship that has grappled with how to define them. First- and second-wave feminists (e.g., Terman and Miles 1936; Millett 1970) were among the first to question assumptions about men/masculinity and women/femininity, which society often perceived as emerging from innate and fundamental

\footnotetext{
${ }^{3}$ People who are cisgender identify with the gender and sex that they were assigned at birth (Erickson-Schroth 2014, 612).
} 
biological differences. The primary objective for these writers was to challenge the notion that sex characteristics are inherently and inevitably connected to gender roles - in other words, that sex (in its physiological sense) determines gender (in the sense of gendered behaviors and attitudes). For instance, Simone de Beauvoir (1952) put forth the notion that one is not born a woman but becomes one-meaning that femininity is socially constructed. Femininity is not a biological fact but rather a product of a patriarchal society that creates labels, stereotypes, roles, and other preconceived categories it assigns to women based on their physical sex.

In the decades that followed, third-wave feminists began to question this metanarrative approach. Judith Butler (1990) challenged the realist ontological assumptions of Beauvoir and others, arguing that such perspectives continued to dichotomize men and women while naturalizing sex. By defining the term "woman," these feminists, albeit unintentionally, implied that there is a correct and fixed way to be a gendered woman (Butler 1990, 5). Instead, Butler (1990) argues that sex, like gender, is not a prediscursive entity but a normative framework that ultimately justifies the oppression of women, nonheterosexual people, and transgender people. Instead of concentrating on how gender is either rooted in the individual or enacted through institutions, Candace West and Don Zimmerman (1987) proposed the concept of "doing gender," whereby gender is an achieved status. Because individuals evaluate gender in interaction, it is observable in a diverse range of behaviors such as conversation, appearance, activities, gestures, and body language. This interactional aspect both encourages and fortifies gender.

These perspectives, too, have been subject to feminist critique. For instance, theories of intersectionality maintain that analyses of social phenomena should examine overlapping systems of oppression such as racism, sexism, classism, and homophobia (Crenshaw 1991; Collins 2009; Meyer 2012). In relation to transphobic systems of oppression, Joanne Meyerowitz (2002) critiques Michel Foucault's (1978) genealogical assessment in his work on the history of sexuality. Instead, she argues that the restructuring of (trans) sexuality transpired asymmetrically and over a longer period of time, and that it was negotiated through interrelated factors, including race, class, region, and nation.

Others have suggested that social constructionist theories fail to take into account human agency and acts of resistance. Francine Deutsch (2007), for example, argues that the problem with doing gender is that one is judged in accordance with such norms regardless of whether one conforms to gendered norms or resists them. Instead of doing gender, Deutsch and others (Butler 2004; Risman 2009) suggest undoing gender, which refers to social interactions that reduce gender differences in order to create opportunities for 
change. Catherine Connell (2010) takes this idea a step further with her concepts of redoing gender and doing transgender. She contends that trans individuals may redo gender by modifying normative beliefs of gender in their social interactions, even as they may contribute to doing gender in other ways.

Many trans writers have indeed written about the transgressive potential of trans people to undo some elements of the dominant binary gender system. ${ }^{4}$ Others have focused on the affirmation that some trans people find in the current binary gender system, noting that trans people are not solely responsible for reproducing or challenging gender binaries (Namaste 2000, 2011; Serano 2007). This debate is intimately connected to the complicated relationship that trans people, particularly trans women, have to feminism (Serano 2013). As Connell (2010) concludes, even though trans individuals are not always undoing or redoing gender, they are - even more so than their cisgender counterparts - always tasked with navigating between sex, gender, and the expectations associated with each.

This navigation is precisely what this article seeks to explore by looking at how young trans people engaged with different understandings of gender and sex in the CTYHS. The above literature review has illustrated how scholars have theorized sex and gender in ways that have created opportunities to understand and validate trans people's experiences. This scholarship is also a call to think critically about the way that binary sex categories are socially imposed and erase the complexity of human biology, to the detriment of intersex people, whose bodies are often the site of nonconsensual medical interventions (Fausto-Sterling 2012; Davis 2015). By challenging the assumption that gender always flows directly from the sex one is assigned at birth, the writings of these critical gender scholars, feminists, and trans activists make it possible to imagine not only having a gender that differs from one's sex assigned at birth but also having nonbinary and fluid genders. It becomes possible for all individuals to do, undo, and redo these normative gendered states in ways that feel validating to them.

\section{Method}

The Canadian Trans Youth Health Survey was a large bilingual study of the health and well-being of trans and gender-diverse youth (ages 14-25) living in Canada with data collected during 2013 and 2014. Several members of the core research team (which includes the authors) were transgender or gender diverse. We also formed transgender youth advisory groups in British

\footnotetext{
${ }^{4}$ See Bornstein (1995), Califia (1997), Feinberg (1998), and Wilchins (2013).
} 
Columbia, Alberta, Ontario, and Nova Scotia to work with us on developing the survey and to help us to interpret the results. We also shared the survey with health professionals who provided clinical services for transgender youth throughout Canada, and many of these shared the link to our survey with their service users.

The survey involved a comprehensive set of questions about physical health, emotional health, and social factors affecting health (e.g. race/ethnicity, socioeconomic status, geography). We also queried about stigmatizing experiences and factors that build resilience (e.g., supportive family, positive self-esteem, community involvement). A total of 923 people responded to the questionnaire from all ten Canadian provinces and the Northwest Territories. As part of our efforts to determine the best way to ask about gender, we also included multiple questions about gender identity and gendered health that researchers have used in clinical services and in other large-scale health surveys, which were developed with varying degrees of community involvement and limited testing with trans youth. It is important that these questions are acceptable to trans youth, so we sought to evaluate what youth thought of questions. Using a scale of $1-5$, we asked participants to rate how much they liked each question (from "I hated it" to "I liked it a lot") and how much they thought the response options fit them (from "not like me at all" to "very much like me"). We then invited participants to give optional comments about these questions in an open-ended text box, and also provided an open-ended text box for respondents to leave feedback at the end of the survey. The exact questions, their response options, the source of the question, and the number of comments are given in table 1 . The comments from the open-ended text boxes became the data we used for analysis.

In total, 324 participants gave comments for at least one of these gender questions in our survey. Table 2 gives an overview of their demographics. The geographic dispersion of participants across provinces and territories was similar to the general population. In terms of gender, 38 percent were (transgender) boys or men, 13 percent were (transgender) girls or women, and the remaining 49 percent reported other nonbinary gender identities. Among respondents who provided comments, a higher proportion were nonbinary than those who did not provide comments ( 36 percent nonbinary). The average age of participants who provided comments was 20 years old, the same as those who did not provide comments. The most common race/ethnicities reported were white and Indigenous (including First Nations, Inuit, and Métis).

Most large-scale quantitative surveys, like the ones that most of our questions about gender came from, are developed within positivist or postpositivist paradigms that tend to focus on dimensions of identity separately, as if they were unidimensional and mutually exclusive, which often fails to capture 
Table 1. Survey Questions on Gender and Sex, in Order of Presentation

\begin{tabular}{|c|c|c|}
\hline Question & Response Options & $\begin{array}{l}\text { Number } \\
\text { of Comments }\end{array}$ \\
\hline $\begin{array}{l}\text { When a person's sex and gender do not } \\
\text { match, they might think of themselves } \\
\text { as transgender. Sex is what a person is } \\
\text { born. Gender is how a person feels. } \\
\text { Which one response best describes } \\
\text { you? }\end{array}$ & $\begin{array}{l}\text { I am not transgender; I am trans- } \\
\text { gender and identify as a boy or } \\
\text { man; I am transgender and iden- } \\
\text { tify as a girl or woman; I am } \\
\text { transgender and identify in some } \\
\text { other way }\end{array}$ & 214 \\
\hline What sex were you assigned at birth ${ }^{c}$ & Male; Female & 38 \\
\hline $\begin{array}{l}\text { If you are Aboriginal, do you identify } \\
\text { as Two Spirit?d,e }\end{array}$ & No; Yes; I'm not Aboriginal & 77 \\
\hline Do you identify as transgender? ${ }^{\mathrm{d}}$ & No; Yes & 126 \\
\hline $\begin{array}{l}\text { Do you identify as trans*? (Trans* } \\
\text { includes transgender, transsexual, } \\
\text { transitioned, gender queer, and } \\
\text { some two spirited people.) }{ }^{\mathrm{f}}\end{array}$ & No; Yes & 117 \\
\hline $\begin{array}{l}\text { Are you currently living in your felt } \\
\text { gender? }\end{array}$ & Yes, full-time; Yes, part-time; No & 90 \\
\hline $\begin{array}{l}\text { What is your gender identity? (Mark all } \\
\text { that apply) }{ }^{\mathrm{c}, \mathrm{g}}\end{array}$ & $\begin{array}{l}\text { Boy or man; Girl or woman; FTM; } \\
\text { MTF; Trans boy or trans man; } \\
\text { Trans girl or trans woman; Feel } \\
\text { like a girl sometimes; Feel like a } \\
\text { boy sometimes; T girl; Two- } \\
\text { Spirit; Intersex; Crossdresser; } \\
\text { Genderqueer; Gender-fluid; } \\
\text { Gender-creative; Bi-gender; If } \\
\text { we have missed your identity, } \\
\text { please share it }\end{array}$ & 122 \\
\hline
\end{tabular}

a"Youth Risk Behavior Surveillance System" (CDC 2006). This measure was tested with 30 cisgender and transgender adolescents; it was originally developed for use in a selfadministered, anonymous health survey in a population-based adolescent sample.

b“Massachusetts Youth Health Survey" (Massachusetts Department of Public Health, Massachusetts Department of Elementary and Secondary Education 2015).

'TransPULSE Survey (http://transpulseproject.ca/wp-content/uploads/2012/05 /Trans-PULSE-survey-information-only-copy-2012.pdf). For more information, see http://transpulseproject.ca/resources/trans-pulse-survey/.

${ }^{\mathrm{d}}$ From Hastings Street to Haida Gwaii (Smith et al. 2014).

"“Ontario Student Drug Use and Health Survey" (CAMH 2013).

${ }^{\mathrm{f}}$ Item created by research team, based on current language at the time of the survey, in order to test it among youth participants.

gParticipants could choose more than one race/ethnicity. Those who responded as white and one other race/ethnicity are listed here as that other race/ethnicity. Those who responded as more than one nonwhite race/ethnicity were listed as multiethnic (Bauer et al. 2009). 
Table 2. Demographics of the Sample

\begin{tabular}{|c|c|c|c|c|}
\hline Age (\%) & Province (\%) & Race/Ethnicity (\%) ${ }^{a}$ & $\begin{array}{l}\text { Time Living in } \\
\text { Canada (\%) }\end{array}$ & $\begin{array}{c}\text { Language Usually } \\
\text { Spoken at Home (\%) }\end{array}$ \\
\hline $14(2)$ & Alberta (11) & White only (76) & $<1$ year $(1)$ & English only (75) \\
\hline $15(4)$ & British Columbia (25) & Indigenous $(9)$ & $1-2$ years $(1)$ & French only (5) \\
\hline $16(7)$ & Manitoba (4) & Black (2) & $3-5$ years $(3)$ & English and French (9) \\
\hline $17(9)$ & New Brunswick (3) & $\begin{array}{l}\text { Central American/ } \\
\text { South American (1) }\end{array}$ & $\geq 6$ years $(9)$ & $\begin{array}{l}\text { English and another } \\
\text { language (7) }\end{array}$ \\
\hline $18(8)$ & $\begin{array}{l}\text { Newfoundland and } \\
\text { Labrador (4) }\end{array}$ & West Asian or Arab (2) & Entire life (87) & $\begin{array}{l}\text { French and another } \\
\text { language (1) }\end{array}$ \\
\hline $19(13)$ & Northwest Territories (1) & Southeast Asian (1) & & Other (3) \\
\hline $20(9)$ & Nova Scotia $(6)$ & South Asian (2) & & \\
\hline $21(11)$ & Ontario (30) & East Asian (5) & & \\
\hline $22(8)$ & Prince Edward Island $(<\mathrm{l})$ & Multiethnic (3) & & \\
\hline $23(11)$ & Québec (14) & Other (1) & & \\
\hline $24(10)$ & Saskatchewan (3) & & & \\
\hline $25(9)$ & & & & \\
\hline
\end{tabular}

Note: Participants could choose more than one identity. Those who responded as white and one other race/ethnicity are listed here as that other race/ethnicity. Those who responded as more than one nonwhite race are listed as multiethnic.

people's complex experience of their identities. Drawing on the insightful work of Lisa Bowleg (2008), our epistemological approach to the data is to undertake a mixed methodological approach via a largely quantitative survey with qualitative narratives in order to provide a "contextualized scientific method" (Bowleg 2008, 320). As Jeanne Marecek (2003, 63) writes: “Whether numbers or words, data do not speak for themselves; they acquire meaning only within a framework of interpretation created by the researcher." By examining how participants speak back to the way we collected data, we seek to draw attention to researchers' frameworks of interpretation that shape these questions, as well as the way that they are experienced by youth.

We used thematic analysis to interpret the comments. Thematic analysis is a qualitative research method that aims to identify, analyze, and report patterns in the data (Braun and Clarke 2006,79). Our approach was both inductive and deductive, meaning that we developed themes linked to the data themselves and informed by our team's theoretical interest in how best to account for gender in research. Our analytical approach was semantic in that we identified themes "within the explicit or surface meanings of the data" (Braun and Clarke 2006, 84). Although our focus is on explicit meanings, we also offer some theoretical insights into the significance and implications of what youth shared with us. 
We faced a few challenges analyzing the data. The first was the anonymous online format. Many of the comments respondents provided were brief, singlesentence answers. Furthermore, participant attrition, which is common in large online youth health surveys, meant that questions presented later in the survey often had fewer responses. Unlike in-depth interviews where researchers can probe for further clarification and detail, researchers have little control over whether or how participants answer questions on online surveys. The second challenge concerns our sampling strategy. Given the small size of the Canadian trans youth population, we used a convenience rather than a purposive sampling approach. Although this yielded a relatively diverse sample, it was not necessarily representative. Despite our best efforts, this made it difficult for us to establish clear patterns among respondents' answers according to race/ethnicity, age, or province (we did not ask questions about income or socioeconomic status). We have indicated areas where patterns existed by gender, with the exception of transfeminine identities. Because transfeminine respondents left the fewest comments, we were hesitant to make claims based on a comparatively smaller data set. Instead, we selected comments to quote in this article to reflect the diversity of genders and location across many provinces.

\section{Findings}

In the next sections, we review the different ways that youth discussed gender and sex in response to our questions. Finding common terminology is not easy: David Valentine (2007) traces the complexity of "transgender" as a collective category for self-identity and activism rooted in various histories and cultures. Meanings about trans identities continue to fluctuate depending on context as well as personal and political goals. For example, people may identify themselves differently on a survey than they do in their local communities depending on trust levels or if they deem it important for researchers to "count" them in a particular way. Some of our respondents spoke explicitly to the uncertainty they felt about what language to use: one respondent noted that he had witnessed "a massive controversy . . . about what the terms 'transgender,' 'transsexual,' 'trans*,' and 'ftm' mean" (20, transmasculine, BC). Although we cannot know about the specific tensions behind this respondent's comment, his words highlight continuous movement and struggle around how people create meaning from these categories. These types of tensions can be the result of the multiple ways of talking about gender and sex that we trace in this article. While some youth drew on the language of social construction to affirm their identities and question gendered and sexed binaries, others embraced binary gender terms 
while distancing themselves from any trans-related labels. Some also evoked modern essentialist understandings of gender and sex to define themselves through the notion of transsexualism. These different articulations suggest different ways of redoing (or undoing) gender through language, with a shared goal of affirming the legitimacy of trans people's genders.

\section{Using social construction to assert the truth of gender}

A number of youth - especially nonbinary youth - used the language of social construction explicitly in their comments. Stating, for example, that "sex and gender are social constructs" (14, nonbinary, Ontario) and that "sex is not 'what a person is born,' sex is a made up (white, colonialist) idea" (17, nonbinary, Ontario), many youth directly responded to a question that started with a purposefully simplistic definition: "When a person's sex and gender do not match, they might think of themselves as transgender. Sex is what a person is born. Gender is how a person feels." Many respondents disliked this definition, reading it as "essentialism" (24, nonbinary, Alberta). In other words, youth perceived this question as reinforcing the notion that sex assigned at birth is the original "truth" of a person, as this comment shows: "What I don't like about this question is how it insinuates that the sex you are assigned at birth is more natural than your gender identity" (24, transfeminine, Ontario). This definition was interpreted as framing sex as more legitimate than gender. This is likely because of the opposition between the verbs "to feel" and "to be," given that what someone feels (here, gender) is often seen as less fundamental than what someone is (here, sex).

In rejecting what they saw as the implied naturalness of sex, youth-especially those over the age of 18 - explicitly referred to the power of authority figures such as doctors to determine the "truth" of someone's sex: "Sex is not just what someone is born, it is what they are assigned by doctors and society at large" (23, nonbinary, Québec). They often challenged this institutional power, as this 25-year-old transmasculine respondent from Ontario did: "Your definitions of sex and gender were very clinical and reflect the institutional discrimination of trans people on the part of the medical and psychiatric institutions. It assumes that the sex doctors assigned a person at birth is the 'right' sex." By describing sex as assignment - an interpretative process that assumes that certain external physiological characteristics are inherently connected to one of two dimorphic sexes and to their related binary gender categories - youth explicitly challenged the common understanding of sex as a straightforward factual description of bodies. As one 20-year-old transfeminine youth from Ontario explained, "sex is not gendered, it just means someone has certain body parts but they do not have a gender inherently attached to them." In other 
words, "physicians conflate sex \& gender when they declare us 'boy' or 'girl' " (24, nonbinary, BC). In critiquing the survey questions in this way, youth demonstrated an awareness and refusal of the cisnormative assumption that sex characteristics inevitably define gender. ${ }^{5}$ And although their comments rarely mentioned this lineage explicitly, they also echo antiessentialist counternarratives developed by critical gender scholars, feminists, and trans activists to challenge dominant understandings of gender and sex.

\section{Questioning the sex binary}

Emphasizing gender as a medical and social process, some youth went beyond challenging the primacy usually given to a person's sex assigned at birth. Instead, they offered a larger critique of sex as "just as much constructed as gender" (23, nonbinary, Ontario), characterizing both as "free flowing" and "never fixed" (19, transfeminine, Atlantic Provinces). Specifically, they questioned sex as binary or that there are only two sexes. As one 19-year-old transmasculine youth from British Columbia noted, "the notion of 'sex' is made up by society based on a variety of traits which give more variety than what two binary ideas of gender allow (chromosomes, genitals, hormone levels, etc.)." These comments echo academic and activist challenges to the bioessentialist notion that binary sex assignments are straightforward, objective descriptions of "purely" biological differences. Anne Fausto-Sterling (2000, 2012), for example, has long questioned how science frames sex as a binary category while neglecting the complexities of the sex-based spectrum and its many variables (see especially Fausto-Sterling 2012). The following comment makes this critique explicit by using academic language: "Sex is a social construct and no one is born with one, they're assigned one by the people around them. . . Bioessentialism ('born as' $[\mathrm{sex}]$ ) and the sex binary are cissexist" (22, nonbinary, Ontario). This comment both criticizes the notion that sex is an innate and fixed part of who we are (bioessentialism) and the notion that sex is a binary. In doing so, this comment evokes Butler's (1990) argument that it is the understanding of gender as a fixed binary that makes sex intelligible as such, rather than the other way around.

Others discussed the mutability of sex. As one youth commented, "sex isn't only what we are born as. We can change our sex. Also, we can define our own sex. It's worth reconsidering the definition of sex a little bit more"

\footnotetext{
${ }^{5}$ Greta Bauer at al. define "cisnormativity" as the expectation that "those assigned male at birth always grow up to be men and those assigned female at birth always grow up to be women" $(2009,356)$.
} 
(24, transmasculine, Atlantic Provinces). ${ }^{6}$ This comment takes the possibility of self-determination even further-although it is not clear exactly what this self-determination would look like when it comes to sex rather than gender. While some aspects of sex can be altered, others (such as chromosomes) cannot. What may be possible, however, is to rethink what appropriate sexed bodies look like and to expand the definitions of "female" or "male" bodies. Although very few youth mentioned intersex people explicitly, this comment and others also call to mind the work of intersex academics and activists who contest how medical impositions and surgical interventions shape bodies into binary compliance (Davis 2015; Wilcox, Côté, and Pagé 2015). It is also possible that the young person who wrote this comment used "sex" and "gender" interchangeably, without distinguishing between them. While there is too little context to determine that with certainty, this ambiguity highlights the difficulty of discussing gender and sex when speakers frequently conflate them in everyday language and imbue them with different meanings.

The comments discussed in the past two sections challenge commonplace, binary understandings of sex and gender by emphasizing both as socially constructed. In this sense, these comments speak to the complexity of finding clear and shared definitions at a time when they are in constant flux. These comments also express a desire to foreground the rights of trans people to define their genders and sexes on their own terms. Although it is not always clear from the short comments exactly how youth envision this self-determination, this perspective clearly seeks to legitimize the genders of trans people while making space for nonbinary, intersex, and gender-nonconforming subjectivities.

\section{Asserting gender as a fact}

The importance of being able to assert one's gender was also present in comments that did not explicitly draw upon the language of social construction. For example, several comments expressed a dislike for the phrase "gender is how a person feels." These youth argued against the notion that gender is something that they feel rather than something that simply is. "Gender isn't a feeling," explained a 15-year-old transmasculine respondent from Ontario. Another respondent expanded on this sentiment: “sometimes when people describe gender identity as a 'feeling,' I feel as though it minimises my identity and makes it come off to others that I am not really a man, and that I just feel

\footnotetext{
${ }^{6}$ Due to low number of respondents, we aggregated quotes from the four Atlantic Provinces (New Brunswick, Prince Edward Island, Nova Scotia, and Newfoundland and Labrador) as well as the Prairie Provinces of Manitoba and Saskatchewan.
} 
like one" (16, transmasculine, Ontario). In some narratives, respondents used caps lock or other forms of typography to emphasize that using the verb "feel" minimized their gender: "I don't *feel* like a girl, I AM a girl" (19, transfeminine, BC). Others expressed similar frustrations regarding the language of gender identity: "I do not identify as transsexual, I just AM" (19, transmasculine, BC). "What exactly is a transgender identity?, " one 20 -yearold transfeminine youth from Québec wrote: "I am trans* It's a fact, not a choice" (translation ours). ${ }^{7}$

These comments express concerns about how, for "all the [political] power of transgender as a category of identity" (Valentine 2007, 6), language can also minimize the legitimacy of trans people's genders in a society where trans repudiation is institutionalized (Namaste 2000; Shelley 2008; Spade 2011). By rejecting the language of feeling and identity, trans youth indirectly asserted that their genders are as legitimate as cisgender people's whose identities as men and women society often treats as self-evident. In some ways, these comments are a reminder that, while doing gender might be "particularly salient" (Vidal-Ortiz 2009, 100) for trans people, drawing unwanted attention to trans peoples' genders can simplify lived experiences and reinforce unwelcome distinctions.

Those who rejected the language of feeling or identity to talk about gender often offered alternative conceptualizations. Some responded by emphasizing the both/and nature of their identities:

I don't necessarily identify as transgender because I am a girl, but am also transgender. (18, transfeminine, BC)

I am a girl who is transgender. It's not just a way I identify, it is what I am. I am a transgender girl. (19, transfeminine, BC)

Others responded by distancing themselves from trans-specific language entirely. As one youth explained, "some people that are trans do not like to be called trans they prefer to be [known] as who they are and not labeled as trans or any of that stuff" (17, transfeminine, Ontario). Those who rejected categories such as trans, trans* ${ }^{*}$ or transgender often preferred to use binary gender labels instead:

I usually just say "I'm a dude" because I'm binary trans and my parts don't always need introduction. (19, transmasculine, Prairie Provinces)

\footnotetext{
${ }^{7}$ The original French reads: "Mais, c'est quoi exactement une identité transgenre? Je suis trans* C'est un fait, c'est pas un choix."
} 
I identify as a woman, but not really as Transgender. I didn't choose to be born in the wrong body and I don't understand how I could consider myself as having a Trans* identity. (20, transfeminine, Québec $)^{8}$

I identify as a girl, not as the [transgender] label. I'm not "guy that wants to be a girl," I'm a "girl with messed up genes." (19, transfeminine, Québec)

I don't like to use the word trans to describe myself, but simply see myself as a man with a history of transition. (20, transmasculine, Ontario)

As the last comment suggests, this distancing from trans labels was often connected to a linear understanding of transition as a journey with a beginning, a middle, and an end. The end of one's transition frequently marks the moment that trans labels become irrelevant:

I'm technically trans and have transitioned, but I don't identify as transgender anymore. (25, transmasculine, Atlantic Provinces)

When I went full-time, I stopped telling people I was trans and only identify as female. (23, transfeminine, Prairie Provinces)

I see transgender more as a state of being when in flux than an identity. I identify as female, yet while transitioning I am transgender. Once my surgery is complete, I will no longer be in flux, and as such I will no longer be transgender. (19, transfeminine, BC)

In these comments, youth acknowledge a connection between past and present but only to assert that trans identification no longer matters.

This distancing is only available for those who engage in binary transitions and can be read as (cisgender) men and women, as this comment illustrates: "many people just want to pass and once they have transitioned they do not really want to be separated out from cis people" (23, transmasculine, Québec). In a cisnormative society where only binary genders are intelligible, nonbinary people do not experience transition in a way that their gender will ultimately be read accurately or unremarkably by other people. They will always be "separated out from cis people." Nonbinary respondents regularly noted this difficulty in response to a question about whether they currently lived in their felt gender: "I'm nonbinary/genderqueer. Most days I feel like there is no way

\footnotetext{
${ }^{8}$ The original French reads: "Je m'identifie comme femme, mais pas vraiment comme Transgenre. Je n'ai pas choisi de naître dans le mauvais corps et je ne comprends pas comment je pourrais considérer que j'ai une identité Trans*”; translation ours.
} 
for me to actually live in my 'felt gender' in a way that other people can understand when they look at me" (21, nonbinary, Atlantic Provinces).

Being able to distance oneself from trans labels often implies having the means to blend into a world of binary gender norms. The means can be material (i.e., access to hormonal, cosmetic, and/or surgical interventions) and/ or social (i.e., having a supportive family to facilitate access to social transition before puberty). Unequal distribution of these means suggests that we cannot disentangle the social and institutional contexts shaping peoples' complex relationships with trans labels (Valentine 2007) and underlines the need for further analysis that can take an intersectional approach. Unfortunately, the type of data and makeup of our sample made it difficult for us to substantiate patterns between youth of different racial/ethnic, class, or geographic backgrounds.

Although no participant expressed a sense of superiority with respect to their distancing from trans labels, it is worth acknowledging that a cultural emphasis on being read as cisgender has historically created hierarchies between those who can do so and those who cannot, or will not (Shelley 2008). Such distancing is highly ambivalent because it can be both a strategic and divisive practice. Passing as a cisgender person, for example, can be a survival strategy for helping trans individuals navigate potentially risky spaces like gender-segregated washrooms - even as this distancing can also effectively renaturalize binary gendered norms. Although binary trans people should be no more responsible for challenging the gender binary and gendered norms than anyone else, it is important to pay attention to how inequalities play out within trans populations and who might be privileged by certain narratives of gender. This would draw our attention to how such divisions, for example, may risk marginalizing underprivileged trans and/or nonbinary people.

\section{Bioessentialism: Transsexualism as a medical condition}

Finally, some youth - especially transmasculine respondents-expressed a preference for the term "transsexual" over transgender or trans*. For them, this term made a clear distinction between gender and sex, which clarified that their problem comes from their sex (as physical characteristics and/or birth assignment) and not their gender:

i prefer the word "transsexual" as i am adjusting my physical sex rather than gender presentation, role or identity. (21, transmasculine, BC)

I prefer to call myself transsexual, since my problem is that I would like to change my sex. (15, transmasculine, Ontario) 
I am a transsexual man. My issue lies in my physical sex. I am not transgender because my issues do not lie with my gender. (19, transmasculine, BC)

Technically I am a transsexual female. My sex is changing from $\mathrm{mtf}$. My gender [has] not change[d] at all, it's female already. (14, transfeminine, Ontario)

I identify as transsexual, and not as transgender. My gender is binary and has never changed. I am only adapting my body. (24, transmasculine, Québec $)^{9}$

In these narratives, gender is framed as an unchangeable fact. Sex, however, can change, and youth specifically mentioned access to medical interventions (especially gender-affirming surgery) as a means to correct their "sex":

Since I am [pursuing] surgery, I am transsexual, not transgender. (18, transmasculine, BC)

I prefer the term transsexual, personally. As it is not just my gender that I feel is opposite but my sex. I have also had surgery. (20, transmasculine, $\mathrm{BC}$ )

Transsexual refers to changing the physical characteristics of sex, which is what I have done via medical transition. My gender has always been male, my sex at birth was wrong. Therefore I identify as a man who has the medical condition of being transsexual. (24, transmasculine, BC)

The last comment makes clear that this perspective was intertwined with a medicalized framework. Several youth called transsexuality a "medical condition" (19, transmasculine, BC) or "birth defect" (25, transfeminine, Ontario), while others compared themselves to people who have a cleft palate or cancer. Within this framework, the condition of transsexualism is a medical problem with a medical solution. The following comment encapsulates such logic: "Gender is neurological sex. When this does not match the body, this causes dysphoria, which is alleviated by transition. I do not like the 'identity' model, as there is nothing spiritual about this medical condition" (15, transmasculine, Ontario). As the above comment shows, such medicalization often comes with a rejection of what this young person calls the "identity" model," which we discussed in the previous section.

\footnotetext{
9 The original French reads: "Je m'identifie comme transsexuel, et non transgenre. Mon genre est binaire et n'a jamais changé. Je n'adapte que mon corps"; translation ours.
} 
In foregrounding medicine and framing gender as a fixed biological fact, these comments draw a clear separation between trans people who alter their sexed bodies via medical interventions and those who do not. They often naturalize gender by affirming its truth through a biological basis, often located in the brain, as in this comment: "I don't agree with this 'gender identity' nonsense. some important bits of my brain are male, but the rest of my body is female, which causes me discomfort" ( 15 , transmasculine, Ontario). "Sex is physical, Gender is mental," wrote one 19-year-old transfeminine youth from Québec. "Note that while sex can be changed somewhat, gender CANNOT be changed; thus the issue." This essentialist view of gender as hardwired, which implies sexual dimorphism (the existence of distinct "male" and "female" brains), has been contested and refuted by numerous scholars. ${ }^{10}$ These comments build toward a fixed notion of gender, reliant on biology to assert itself as real. In contrast, elements constitutive of sex (anatomy and hormones) are framed as modifiable or even fixable by medicine.

\section{Discussion}

We have presented a range of views on gender and sex that young people shared in the CTYHS. In comments that drew on the lens of social construction, both sex and gender come under scrutiny as being dependent on human interpretation and social context. As a result, definitions of sex and gender varied among youth. Some insisted on differentiating the two terms, while others seemed to collapse them. For some youth, it was crucial to talk about gender rather than sex; for others, it was simply a question of clarifying that gender determines sex and not the other way around. The organizing principle across the social construction comments was that because sex and gender are contingent on social definitions (rather than objective reality), selfdefinition should be prioritized. As a result, many comments written from that perspective implicitly and sometimes explicitly embraced the multiplicity of genders and sexes.

In comments that drew instead on the language of bioessentialism, gender was framed as the core of a person's truth: gender is an objective and unchangeable fact about someone, while sex is malleable - specifically modifiable via medical interventions. This perspective complicates the traditional script of biological essentialism, which locates the "truth" of the gendered self in sex (including reproductive organs, hormones, and chromosomes).

\footnotetext{
${ }^{10}$ See Fausto-Sterling (2000), Hubbard (2001), Fine (2011), Gauthier (2014), and Saewyc (2017).
} 
Sari Van Anders (2014) describes several forms of "bio/logics" that are "implicit and/or explicit reasoning guides informed by features thought to be natural, corporeal, evolved, and material" (33). These make it difficult to recognize gender/sex transitions because they define sex (and thus gender) through features that are mostly unchangeable: interior bio/logics give primacy to the least changeable or visible corporeal features of sex (i.e., genes); trace bio/logics treat gender/sex as immutable by privileging "corporeal features that influence later sex development ... as determinants of gender/sex" (i.e., hormones released from gonads; 34); and newborn bio/logics prioritize the sex assignment made by doctors at birth, based on the displayable body.

While youth in the CTYHS generally refused these three specific forms of bio/logics and their denial of trans subjectivities, they did not refuse the underlying principle that "biological factors are both deterministic to and the essence of specific human phenomena" (Van Anders 2014, 33). Instead, some saw the brain and its wiring as the biological factor most deterministic of a person's sex/gender. Building on Van Anders's typology, this understanding of gender/sex could be called "cognitive bio/logics"—one that relies on a primacy of biology but favors the brain as the location of fundamental truth. On the surface, cognitive bio/logics is compatible with some of the criticisms of essentialism that feminists, gender scholars, and trans activists have articulated over the years. Yet instead of questioning who has the power of definition, it reinvests truth in a different location. Some participants who articulated such perspectives did so alongside a belief that medical authority can renaturalize trans people's sex through surgico-medical interventions, thereby voiding the original—and incorrect—sex assignment made at birth. This suggests that cognitive bio/logics might be compatible with a rearticulation of newborn bio/logics and its exteriorization of the truth of gender/sex in the displayable body.

This shift in essentialist discourse is not unique to these youth. It is reflected in popular discourse through narratives of "being born in the wrong body" or having a "boy brain in a girl's body" as well as much of the medical literature on the cognitive origins of gender identity disorder going back several decades (Money 1994; Swaab 2004; Nota et al. 2017). As we note above, cognitive bio/logics share foundational assumptions with a larger popular-scientific discourse that asserts the existence of fundamental differences in female and male brains (Hines 2010; Miller and Halpern 2014). Our purpose in this article is not to add to existing critiques of various forms of bioessentialism. ${ }^{11}$ Rather, we aim to capture the ways some youth have adapted essentialist discourse

\footnotetext{
${ }^{11}$ See Fausto-Sterling (2012), Fine (2014), Gauthier (2014), and Roy (2016).
} 
to a cultural context that increasingly recognizes trans subjectivities. In a context receptive to this line of argument, essentialist arguments can be "not only a necessary evil, but positively desirable" (Jansen 2016, 123).

Whether they drew on social constructivist, essentialist, or mixed perspectives, all the comments by youth on the CTYHS shared a key commitment to trans people's claims for legitimacy by asserting that the genders of trans people are real. Youth differed in how they articulated that commitment: by questioning how the categories of sex and gender come to be understood, by questioning the language we use to talk about gender and sex, or by shifting the location of the true gendered self (in the features of the brain rather than in bodily characteristics assigned to binary sexes). Despite some fundamental differences, these perspectives all respond to the denial of trans subjectivity that has defined trans people's experiences in our society (Namaste 2000; Shelley 2008; Spade 2011). Based on quantitative ratings, youth rated lowest $(2.49 / 5)$ and provided one of the fewest numbers of comments $(n=38)$ to the question about sex assigned at birth-perhaps another indication of the concern and frustration that all youth felt toward questions that they read as failing to give primacy to trans people's own sense of self.

A key distinction between these perspectives is the room they make for genders and sexes beyond binaries. By virtue of its questioning of existing categories, the social construction perspective easily accommodates the idea of gender and sex as spectra rather than binaries. Gender and sex spectra make it possible to acknowledge nonbinary as well as intersex subjectivities, although youth rarely explicitly discussed the latter. Comments from our nonbinary youth respondents often used the language of social construction, suggesting that it resonated with their experiences.

In contrast, the desire to reject trans labels highlights the privileging of trans subjectivities that are more easily integrated into the existing binary gender system after transition. The language of bioessentialism validates these experiences without clearly acknowledging nonbinary genders. Indeed, theories that argue gender has a biological basis in the brain have historically been tightly attached to binary conceptions of gender (Fausto-Sterling 2000). One of our respondents explicitly demonstrated this by claiming that there is "no scientific evidence" that nonbinary genders exist, adding "gender-creative isn't a real thing" (19, transmasculine, BC). The data limits our capacity to analyze the institutional and social factors that shape how youth come to articulate their experiences through a bioessentialist lens. Regardless, this neoessentialist framework risks creating a hierarchy of legitimacy that privileges trans people whose gender can be located in some aspects of the brain according to established cisnormative frameworks of science; namely, trans people whose brains 
resemble those of their cisgender counterparts (Rametti et al. 2011). Within the realm of research, it encourages investigative and analytical approaches that ignore and render invisible both intersex and nonbinary people who do not have cisgender counterparts to legitimize their existence (Frohard-Dourlent et al. 2016).

The work of critical gender scholars, feminists, and trans activists seems to have had an impact on multiple perspectives discussed in this article. These often-overlapping groups have long been in dialogue as well as tension with each other (Enke 2012; Serano 2013), helping shift discourses about gender by questioning and challenging assumptions about the immutability of the cisnormative gender order. Over the course of the past fifty years, these theoretical challenges have slowly opened up possibilities for new subjectivities while giving more space to trans perspectives. This legacy is most obvious in the social construction perspective that some youth articulated: their language and arguments echoed gender scholarship and activism, although it is impossible for us to explain where they acquired this fluency. The perspective of bioessentialism, however, has also integrated some feminist insights on gender and sex in order to account for trans lives. Specifically, it has incorporated the distinction between sex as physical characteristics and gender as internal sense of self, a definition that has become a staple of introductory social science textbooks (see, e.g., Little 2013). This perspective, for which we owe thanks to early feminism (e.g., Beauvoir 1952), was crucial in challenging the assumption that sex determines how one acts or should act - even as it left sex an unquestioned biological category (Fausto-Sterling 2003).

Instead of integrating more recent feminist insights, this modern medical essentialism appropriates early feminist discourse to locate a biological essence in gender rather than in sex. This neoessentialism may have some political efficacy in certain contexts but may also come at the price of relinquishing the authority of whose bodies and genders matter (and thus, whose do not) to medical professionals. Experiences from the LGBQ movement and critiques of the "born this way" narrative warn us about how this type of essentialism can redraw the boundaries of legitimacy rather than expand them in an inclusive manner (Wade 2011; Walters 2011).

All the perspectives we discussed differ in some way from the stilldominant understanding of gender as immutable, biologically determined, and binary. Although the medicalization of gender diversity likely impacts some trans youth's lived experiences with gender (Johnson 2015), the relationship between the two is not straightforward. Our findings raise the question of how youth come to conceptualize gender in a variety of new ways. Because we lack context for youth respondents' comments, we can only make inferences about how they were exposed to the different perspectives we have 
analyzed in this article. Some possibilities include postsecondary education, involvement in activist circles in person and online, interactions with medical professionals, and general-audience books written by feminist and trans activists as well as psychologists. None of these modes of involvement and interactions would guarantee a uniform perspective of gender, as significant tensions about how to think through gender and sex remain among gender scholars, feminists, and trans activists (Noble 2012; Elliot 2016) as well as in the health care literature (Perone 2014; Dewey and Gesbeck 2017).

\section{Conclusion}

When we started the CTYHS, we knew that asking about gender in largescale population health surveys was a complicated matter. We are not the first ones to ponder this conundrum. ${ }^{12}$ Valentine $(2007,25)$ reminds us that "language is a central site - theoretically, practically, politically, and ethicallyfor the negotiation of meanings in any field." It appears to be especially so in trans-related research, since both the awareness of and the vocabulary surrounding sex and gender are rapidly changing. The comments analyzed in this article show us that there is little youth consensus regarding language or conceptualizations of gender and sex. The same questions were simultaneously praised and criticized by youth, who argued in thoughtful and passionate ways how language reflected (or did not reflect) the truth of their experiences.

These tensions and disagreements also point to the long-noted difficulty that survey methodologies encounter when attempting to collect demographic information about genders and sexualities (Stacey and Thorne 1985; Harding 1987; Westbrook and Saperstein 2015). Yet there is extraordinary energy to be found in how young people engaged with the CTYHS questions. Their comments were a sign of their commitment to making sure that we, the researchers, got feedback on more inclusive, resonant, and accurate ways to ask about their experiences, bodies, and genders. We wanted to write this article not only to explore the multiple ways trans youth talk about gender and sex but also to wrestle with their feedback and consider its implications. The two perspectives discussed are hardly easy to reconcile. The comments left by trans youth show that they, just like larger transgender

${ }^{12}$ See Conron and Austin (2008), Gender Identity in U.S. Surveillance Group (2014), Reisner et al. (2015), and Bauer et al. (2017). 
and cisgender populations, have complicated relationships to, and understandings of, what gender and sex might mean for them. When language fluctuates, it is all the more difficult for researchers (even when they are part of that community) to determine how to engage and formulate their research in a way that is accessible, inclusive, and informative.

We come away from this article not with easy answers but with a renewed commitment to engage with youth as we develop future projects and formulate future surveys. However, this lack of answers should not be read as relativist abdication; just because all language has flaws does not mean that some language is not better than others. When quantitatively rating the CTYHS's gender-related questions (see table 1), youth in the CTYHS indicated a slight preference for questions with the most inclusive definitions and questions with the most options to choose from, including an open-ended field. Most recently, some of the authors on our team have developed a survey on genderaffirming surgery with the trans health program of a local health authority (see Frohard-Dourlent, Coronel Villalobos, and Saewyc 2017). For that survey, having learned from our experience with the CTYHS and having consulted a peer reference group, we chose to ask about gender in a two-step manner. First, we asked people to identify their gender in an open-ended field; then, to look for gendered inequities through quantitative analysis of groups, we asked people to identify with one of three categories: transfeminine/woman/ $\mathrm{MtF}$, transmasculine/man/FtM, and nonbinary/genderqueer. This approach seems to have resonated with our respondents, because it allowed them to express their gender identities in their own words, thus recognizing the complexity of identity and relationships to various identity terms that surfaced among CTYHS respondents. This approach also recognized the researchers' analytical need for categories but did so by empowering participants to choose how they would classify themselves based on three gender options that were inclusive of nonbinary and gender-nonconforming identities. This is preferable to an analyst classifying participants into three options based on the analyst's interpretation of the open-ended responses. This positive outcome encourages us to try a similar approach in the future when we explore this question with youth next time, although the shifting terrain of gender and sex will require us to consult with youth directly again.

School of Nursing

University of British Columbia (Frohard-Dourlent)

School of Nursing

University of British Columbia (Saewyc) 
School of Psychology

Waikato University (Veale)

Department of Sociology

University of Manitoba (Peter)

School of Nursing

University of British Columbia (MacAulay)

\section{References}

Bauer, Greta R., Rebecca Hammond, Robb Travers, Matthias Kaay, Karin M. Hohenadel, and Michelle Boyce. 2009. “'I Don't Think This Is Theoretical; This Is Our Lives': How Erasure Impacts Health Care for Transgender People.” Journal of the Association of Nurses in AIDS Care 20(5):348-61.

Bauer, Greta R., Jessica Braimoh, Ayden I. Scheim, and Christoffer Dharma. 2017. "Transgender-Inclusive Measures of Sex/Gender for Population Surveys: Mixed-Methods Evaluation and Recommendations." PLOS ONE 12(5): e0178043. https://doi.org/10.1371/journal.pone.0178043.

Beauvoir, Simone de. 1952. The Second Sex. New York: Knopf.

Bornstein, Kate. 1995. Gender Outlaw: On Men, Women, and the Rest of Us. New York: Vintage.

Bowleg, Lisa. 2008. "When Black + Lesbian + Woman $\neq$ Black Lesbian Woman: The Methodological Challenges of Qualitative and Quantitative Intersectionality Research." Sex Roles 59(5-6):312-25.

Braun, Virginia, and Victoria Clarke. 2006. "Using Thematic Analysis in Psychology." Qualitative Research in Psychology 3(2):77-101.

Butler, Judith. 1990. Gender Trouble: Feminism and the Subversion of Identity. New York: Routledge.

. 2004. Undoing Gender. New York: Routledge.

Califia, Patrick. 1997. Sex Changes: The Politics of Transgenderism. San Francisco: Cleis.

CAMH (Centre for Addiction and Mental Health). 2013. "Ontario Student Drug Use and Health Survey." https://www.camh.ca/en/science-and-research /institutes-and-centres/institute-for-mental-health-policy-research/ontario -student-drug-use-and-health-survey-osduhs.

CDC (Centers for Disease Control and Prevention). 2006. "Youth Risk Behavior Surveillance System.” 5(SS-5):1-112. https://www.cdc.gov/healthyyouth /data/yrbs/index.htm.

CIHR (Canadian Institutes of Health Research). 2015. "Definitions of Sex and Gender." CIHR, June 17. http://www.cihr-irsc.gc.ca/e/47830.html.

Collins, Patricia Hill. 2009. Black Feminist Thought: Knowledge, Consciousness, and the Politics of Empowerment. 2nd ed. New York: Routledge. 
Connell, Catherine. 2010. “Doing, Undoing, or Redoing Gender? Learning from the Workplace Experiences of Transpeople." Gender \& Society 24(1):31-55.

Conron, Kerith Jane, Scout, and S. Bryn Austin. 2008. “'Everyone Has a Right to, Like, Check Their Box"”: Findings on a Measure of Gender Identity from a Cognitive Testing Study with Adolescents." Journal of LGBT Health Research 4(1):1-9.

Crenshaw, Kimberlé Williams. 1991. "Mapping the Margins: Intersectionality, Identity Politics, and Violence against Women of Color." Stanford Law Review 43(6):1241-99.

Davidson, Megan. 2007. "Seeking Refuge under the Umbrella: Inclusion, Exclusion, and Organizing within the Category Transgender." Sexuality Research and Social Policy 4(4):60-80.

Davis, Georgiann. 2015. Contesting Intersex: The Dubious Diagnosis. New York: New York University Press.

Deutsch, Francine M. 2007. "Undoing Gender.” Gender \& Society 21(1):106-27.

Dewey, Jodie M., and Melissa M. Gesbeck. 2017. “(Dys) Functional Diagnosing: Mental Health Diagnosis, Medicalization, and the Making of Transgender Patients." Humanity and Society 41(1):37-72.

Elliot, Patricia. 2016. Debates in Transgender, Queer, and Feminist Theory: Contested Sites. New York: Routledge.

Enke, A. Finn, ed. 2012. Transfeminist Perspectives in and beyond Transgender and Gender Studies. Philadelphia: Temple University Press.

Erickson-Schroth, Laura, ed. 2014. Trans Bodies, Trans Selves: A Resource for the Transgender Community. Oxford: Oxford University Press.

Fausto-Sterling, Anne. 2000. Sexing the Body: Gender Politics and the Construction of Sexuality. New York: Basic.

_. 2003. "The Problem with Sex/Gender and Nature/Nurture." In Debating Biology: Sociological Reflections on Health, Medicine, and Society, edited by Simon J. Williams, Linda Birke, and Gillian A. Bendelow, 123-32. London: Routledge.

- 2012. Sex/Gender: Biology in a Social World. New York: Routledge.

Feinberg, Leslie. 1998. Trans Liberation: Beyond Pink or Blue. Boston: Beacon.

Fine, Cordelia. 2011. Delusions of Gender: How Our Minds, Society, and Neurosexism Create Difference. New York: Norton.

—. 2014. "His Brain, Her Brain?” Science 346(6212):915-16.

Foucault, Michel. 1978. The History of Sexuality, volume 1: An Introduction. New York: Vintage.

Frohard-Dourlent, Hélène, Sarah Dobson, Beth A. Clark, Marion Doull, and Elizabeth M. Saewyc. 2016. “'I Would Have Preferred More Options': Accounting for Nonbinary Youth in Health Research.” Nursing Inquiry 24(1):e12150. doi: $10.1111 /$ nin. 12150 .

Frohard-Dourlent, Hélène, Mauricio Coronel Villalobos, and Elizabeth Saewyc. 2017. A Survey of Experiences with Surgery Readiness Assessment and Gender-Affirming Surgery among Trans People in Canada: Focus on British Columbia. Vancouver, BC: Stigma and Resilience among Vulnerable Youth Centre, School of Nursing, University of British Columbia. 
Gauthier, C. Armes. 2014. "Brain Imaging." TSQ 1(1-2):42-45.

Gender Identity in U.S. Surveillance Group. 2014. "Best Practices for Asking Questions to Identify Transgender and Other Gender Minority Respondents on PopulationBased Surveys.” Los Angeles: Williams Institute. https://williamsinstitute.law .ucla.edu/wp-content/uploads/geniuss-report-sep-2014.pdf.

Grant, Tavia. 2018. "Statistics Canada Begins Testing Nonbinary Gender Options in Surveys." Globe and Mail, May 13, 2018. https://www.theglobeandmail.com /canada/article-statistics-canada-begins-testing-nonbinary-gender-options-in -surveys/.

Harding, Sandra G., ed. 1987. Feminism and Methodology: Social Science Issues. Bloomington: Indiana University Press.

Hines, Melissa. 2010. "Sex-Related Variation in Human Behavior and the Brain." Trends in Cognitive Sciences 14(10):448-56.

Hubbard, Ruth. 2001. "Science and Science Criticism." In The Gender and Science Reader, edited by Muriel Lederman and Ingrid Bartsch, 49-51. London: Routledge.

Jansen, Sebastian. 2016. "Transgender and Intersex: Unavoidable Essentialism and the Normative Struggle for Recognition." In Transgender and Intersex: Theoretical, Practical, and Artistic Perspectives, edited by Stefan Horlacher, 115-40. New York: Palgrave Macmillan.

Johnson, Austin H. 2015. "Normative Accountability: How the Medical Model Influences Transgender Identities and Experiences." Sociology Compass 9(9):803-13.

Kupfer, Matthew. 2016. "Transgender Student Says Some Canadians Need 3rd Option for Gender on Census." CBC News. January 6. http://www.cbc.ca/news /politics/quinn-nelson-transgender-canadians-census-1.3392218.

Little, William. 2013. Introduction to Sociology: 1st Canadian Edition. Houston: Rice University.

Marecek, Jeanne. 2003. "Dancing through Minefields: Toward a Qualitative Stance in Psychology." In Qualitative Research in Psychology: Expanding Perspectives in Methodology and Design, by Paul M. Camic, Jean E. Rhodes, and Lucy Yardley, 49-69. Washington, DC: American Psychological Association.

Massachusetts Department of Public Health, Massachusetts Department of Elementary and Secondary Education. "Massachusetts Youth Health Survey (Winter 2015)." 2015. Available at https://www.mass.gov/doc/youth-health-survey -questionnaire-high-school-2015-0/download (accessed June 20, 2020).

Meyer, Doug. 2012. "An Intersectional Analysis of Lesbian, Gay, Bisexual, and Transgender (LGBT) People's Evaluations of Anti-Queer Violence." Gender es Society 26(6):849-73.

Meyerowitz, Joanne J. 2002. How Sex Changed: A History of Transsexuality in the United States. Cambridge, MA: Harvard University Press.

Miller, David I., and Diane F. Halpern. 2014. "The New Science of Cognitive Sex Differences." Trends in Cognitive Sciences 18(1):37-45.

Millett, Kate. 1970. Sexual Politics. Garden City, NY: Doubleday.

Money, John. 1994. "The Concept of Gender Identity Disorder in Childhood and Adolescence after 39 Years." Journal of Sex and Marital Therapy 20(3):163-77. 
Namaste, Viviane K. 2000. Invisible Lives: The Erasure of Transsexual and Transgendered People. Chicago: University of Chicago Press.

2011. Sex Change, Social Change: Reflections on Identity, Institutions, and Imperialism. 2nd ed. Toronto: Women's Press.

Noble, Bobby. 2012. "Trans. Panic. Some Thoughts toward a Theory of Feminist Fundamentalism." In Enke 2012, 45-59.

Nota, Nienke M., Baudewijntje P. C. Kreukels, Martin den Heijer, Dick J. Veltman, Peggy T. Cohen-Kettenis, Sarah M. Burke, and Julie Bakker. 2017. "Brain Functional Connectivity Patterns in Children and Adolescents with Gender Dysphoria: Sex-Atypical or Not?" Psychoneuroendocrinology 86 (December):187-95.

Perone, Angela K. 2014. "The Social Construction of Mental Illness for Lesbian, Gay, Bisexual, and Transgender Persons in the United States.” Qualitative Social Work 13(6):766-71.

Rametti, Giuseppina, Beatriz Carrillo, Esther Gómez-Gil, Carme Junque, Santiago Segovia, Ángel Gomez, and Antonio Guillamon. 2011. "White Matter Microstructure in Female to Male Transsexuals before Cross-Sex Hormonal Treatment: A Diffusion Tensor Imaging Study.” Journal of Psychiatric Research 45(2):199-204.

Reisner, Sari L., Kerith J. Conron, Scout, Kellan Baker, Jody L. Herman, Emilia Lombardi, Emily A. Greytak, Alison M. Gill, and Alicia K. Matthews. 2015. “'Counting' Transgender and Gender-Nonconforming Adults in Health Research: Recommendations from the Gender Identity in US Surveillance Group." TSQ2(1):34-57.

Risman, Barbara J. 2009. "From Doing to Undoing: Gender as We Know It." Gender \& Society 23(1):81-84.

Roy, Deboleena. 2016. "Neuroscience and Feminist Theory: A New Directions Essay." Signs: Journal of Women in Culture and Society 41(3):531-52.

Saewyc, Elizabeth M. 2017. "Respecting Variations in Embodiment as Well as Gender: Beyond the Presumed 'Binary' of Sex.” Nursing Inquiry 24(1):e12184.

Serano, Julia. 2007. Whipping Girl: A Transsexual Woman on Sexism and the Scapegoating of Femininity. Emeryville, CA: Seal.

- 2013. Excluded: Making Feminist and Queer Movements More Inclusive. Berkeley, CA: Seal.

Shelley, Christopher. 2008. Transpeople: Repudiation, Trauma, Healing. Toronto: University of Toronto Press.

Smith, A., D. Stewart, C. Poon, M. Peled, E. Saewyc, and McCreary Centre Society. 2014. From Hastings Street to Haida Gwaii: Provincial Results of the 2013 BC Adolescent Health-Survey. Vancouver: McCreary Centre Society. Available at https://www.mcs.bc.ca/pdf/From-Hastings-Street-to-Haida-Gwaii.pdf.

Spade, Dean. 2011. Normal Life: Administrative Violence, Critical Trans Politics, and the Limits of Law. Brooklyn, NY: South End.

Stacey, Judith, and Barrie Thorne. 1985. "The Missing Feminist Revolution in Sociology." Social Problems 32(4):301-16.

Swaab, D. F. 2004. "Sexual Differentiation of the Human Brain: Relevance for Gender Identity, Transsexualism, and Sexual Orientation." Gynecological Endocrinology 19(6):301-12. 
Terman, Lewis M., and Catharine Cox Miles. 1936. Sex and Personality: Studies in Masculinity and Femininity. Vol. 11. New York: McGraw-Hill.

Valentine, David. 2007. Imagining Transgender: An Ethnography of a Category. Durham, NC: Duke University Press.

Van Anders, Sari M. 2014. "Bio/Logics.” TSQ 1(1-2):33-35.

Vidal-Ortiz, Salvador. 2009. "The Figure of the Transwoman of Color through the Lens of 'Doing Gender.'” Gender \& Society 23(1):99-103.

Wade, Lisa. 2011. "Are We Born Gay? And If We Were, How Would We Know?" Sociological Images, February 21. https://thesocietypages.org/socimages /2011/02/21/are-we-born-gay-and-if-we-were-how-would-we-know/.

Walters, Suzanna Danuta. 2011. "Born This Way?” Chronicle of Higher Education, July 5. http://www.chronicle.com/blogs/brainstorm/born-this-way/37016.

West, Candace, and Don H. Zimmerman. 1987. "Doing Gender." Gender \& Society $1(2): 125-51$.

Westbrook, Laurel, and Aliya Saperstein. 2015. "New Categories Are Not Enough: Rethinking the Measurement of Sex and Gender in Social Surveys." Gender \& Society 29(4):534-60.

Wilchins, Riki. 2013. Read My Lips: Sexual Subversion and the End of Gender. Riverdale, NY: Riverdale Avenue Books.

Wilcox, André, Isabel Côté, and Geneviève Pagé. 2015. "L'enfant intersexué: Dysphorie entre le modèle médical et l'intérêt supérieur de l'enfant" [The intersex child: Dysphoria between the medical model and the best interests of the child]. Intervention 148:65-77. 